\section{EMBRYRIDDLE \\ Aeronautical University}

SCHOLARLY COMMONS
International Journal of Aviation, Aeronautics, and Aerospace

7-12-2018

\title{
Portable Electronic Devices on the Flight Deck
}

Irena Wentzel

Florida Institute of Technology, icwentzel@aol.com

John E. Deaton

Florida Institute of Technology, jdeaton@fit.edu

Follow this and additional works at: https://commons.erau.edu/ijaaa

Part of the Aviation Safety and Security Commons

\section{Scholarly Commons Citation}

Wentzel, I., \& Deaton, J. E. (2018). Portable Electronic Devices on the Flight Deck. International Journal of Aviation, Aeronautics, and Aerospace, 5(3). https://doi.org/10.15394/ijaaa.2018.1221

This Article is brought to you for free and open access by the Journals at Scholarly Commons. It has been accepted for inclusion in International Journal of Aviation, Aeronautics, and Aerospace by an authorized administrator of Scholarly Commons. For more information, please contact commons@erau.edu. 
The ability to discern when the use of an electronic device is acceptable or inappropriate is not always as easy as it seems. When it comes to professional pilots, many organizations have clear-cut definitions of when the use of portable electronic devices (PEDs) are prohibited. Despite these policies, many pilots will still use their device(s) either as a means of communication or entertainment during the flight. Now that electronic flight bags (EFBs) are used at most airlines, it recently became necessary to better define the guidelines for approved EFB usage. More specifically, if an EFB is housed in a tablet of some sort, isn't an EFB considered a PED?

To clarify the two and emphasize the importance of this issue, the Federal Aviation Administration (FAA) updated the Advisory Circular (AC) 120-76D: Authorization for the use of Electronic Flight Bags. The AC states that when an EFB is being used for personal functions not related to flight duties, then it becomes a PED (FAA, 2017b). In short, an EFB could be considered a PED depending on how it is being used by the pilot(s); if it is being used by company policy for flightrelated functions only, then it is an EFB and does not apply to this study. If the EFB is being used for functions outside of the scope of approval, then it is considered a PED.

The National Transportation Safety Board (NTSB) recognizes that PED usage is a growing dilemma in all modes of transportation to include rail, marine, air, and roadway as mentioned in the bulletin "Eliminate Distraction in Transportation" bulletin (NTSB, 2014). Since 2003, PEDs have been identified as either a cause or contributing factor in accidents and incidents in all modes of transportation (NTSB, 2014). Because PEDs are so prominent and are likely to cause distraction, the NTSB currently examines what role a PED may have played in every new accident investigation (NTSB, 2014).

\section{Background}

The reliance on electronic devices today has become so prevalent that it is not uncommon to see a room, terminal area, train stop, or sidewalk full of people immersed in their devices. It is almost second nature, so much so that we do not think twice about a whole table of people only interacting with their devices instead of each other during dinner. Studies have shown a link between cell phones and brain chemicals, like dopamine and endorphins, suggesting an actual 'addiction' to the device. Compared to someone who uses a cell phone in moderation, the 'addict' presents a permanent state of awareness of their phone; this leads to the uncontrolled necessity of checking the phone, no matter what they are doing (Paz de la Puente, Balmori, \& Garcia, 2007). The distractions that can be caused by 
electronic devices, specifically smartphones, are so egregious that people have a hard time walking. There are numerous images and videos alike of people tripping, walking into poles, or falling into fountains because they are on their devices.

Now we enter the realm of vehicles and uncover the sad reality of the deaths caused by texting and driving. Electronic devices are meant to help us, not hurt us, but the problem arises when the device is no longer an aid but a distraction. Pilots can access their flight plans, work schedules, current weather, or any other information relevant to the current operation literally with the touch of a few buttons. Again, these resources are great until they become a distraction. The use of electronic devices has become an integral part of daily schedules, but there are still times when their use is inappropriate, dangerous, or prohibited.

There have been several occasions in the last decade where PEDs were involved in aircraft incidents or accidents either directly or latently. On February 12, 2009, 45 passengers and four crewmembers were fatally injured when Colgan Air Flight 3407 stalled on final approach and subsequently crashed just five miles from the field (NTSB, 2010a). It was discovered during the accident investigation that the First Officer (FO) used her cell phone and sent a text message during the taxi out to the runway (NTSB, 2010a). While the use of the cell phone was not causal to the accident, the NTSB Accident Report references the PED activity because it violated AC 91.21-1B: Use of Portable Electronic Devices Aboard Aircraft, published on August 25, 2006 (NTSB, 2010a). This AC was revised to AC 91.21-1D on October 27, 2017, concurrent with AC 120-76D.

The AC mandates that "a cell phone will not be authorized for use while the aircraft is being taxied for departure after leaving the gate. The unit will be turned off and properly stowed to prepare the aircraft for takeoff as per the operator's procedures." (FAA, 2017a). Additionally, the FAA published the Safety Alert for Operators (SAFO) 09003 about a week before the accident on February 4, 2009. The SAFO recommended that all Part 121 and 135 operators review their standard operating procedures (SOPs) to ensure a reminder for crewmembers to turn off their devices and comply with sterile cockpit procedures (FAA, 2009).

Six months after the tragic Colgan accident, a midair collision occurred over the Hudson River in New York City on August 8, 2009. One of the contributing factors of the accident was cited to be the air traffic controller's use of a landline telephone to make a personal call (NTSB, 2010c). The telephone conversation was a distraction that caused the controller to miss the pilot's incorrect frequency read back as well as fail to hand the pilot over to Newark tower promptly (NTSB, 2010c). Though this accident does not involve a PED on the flight deck, it can be 
used as an example of the severity of the risk caused by distractions. Similar distractions could occur while a pilot is engaged with their PED, potentially leading to an incident or accident.

Shortly after the midair collision in New York, Northwest Airlines Flight 188 originating in San Diego made news headlines when it overflew its destination of Minneapolis because the pilots were preoccupied with the bidding software on their laptops (NTSB, 2010b). On October 21, 2009, the pilots flew for an hour and 17 minutes without any contact with air traffic control (ATC), flying as far east as Eau Claire, Wisconsin before realizing their location and that they had not spoken to ATC (NTSB, 2010b). According to the NTSB, the only reason the pilots were alerted to this was that of a call from the flight attendants inquiring about their estimated arrival time. The pilots missed several calls from ATC and their company dispatcher while they were using their laptops, which was against company policy (NTSB, 2010b). Fortunately, there were no injuries because of this incident, but it brought light to a more significant problem: the distractions caused by PEDs on the flight deck.

On August 26, 2011, an air ambulance helicopter crashed due to fuel exhaustion; the pilot was not aware of his fuel state because he was using his cell phone. Tragically, the pilot, two flight nurses, and the patient being transported were killed. The final accident report lists 'distraction due to nonoperational use of portable electronic devices during flight and ground operations' as a contributing factor (NTSB, 2013a). The accident report also revealed the pilot had multiple opportunities to notice the incorrect fuel load before departing but did not because of an inadequate preflight inspection. Cell phone data revealed that the pilot was involved in extensive text activity during the preflight period (NTSB, 2013a). While the accident report does not specify that text message activity resulted in a poor preflight, it can be inferred that it was a distraction at the very least which led to unfortunate circumstances.

On May 20, 2014, the FAA published the Information for Operations (InFO) 14006: Prohibition on Personal Use of Electronic Devices on the Flight Deck. This publication not only included Part 121 and 135 operations but expanded to include Part 91K, or fractional ownership (FAA, 2014b). The bulletin emphasized the prohibition of "personal wireless communications devices or laptop computers for personal use while at their duty station on the flight deck while the aircraft is being operated unless it is by FAA approved operational procedures." (FAA, 2014b). Unfortunately, this publication did not necessarily include Part 91 general aviation flights. 
A little over a week after InFO 14006 was published, a Cessna 150 stalled immediately after departure from Watkins, CO. Both the pilot and passenger were fatally injured around midnight when the aircraft impacted the ground (NTSB, 2015). A GoPro recorder was retrieved from the site and revealed that both occupants of the aircraft were using their cell phones to take selfie photographs during the takeoff roll and climb out (NTSB, 2015). The flight occurred during night instrument meteorological conditions (IMC) and the pilot and passenger were using the flash function on their cameras (NTSB, 2015). It is believed the pilot experienced spatial disorientation due to the camera flash, distraction from the PED at low altitude, and night IMC conditions (NTSB, 2015).

That same year, a helicopter crashed on December 29, 2014, in Lake Worth, FL. Onboard was a student and instructor who were practicing autorotations in the traffic pattern. The instructor was fatally injured, and the student sustained severe injuries (NTSB, 2017). The helicopter suffered a main rotor stall, and the flight instructor failed to recover the aircraft in a timely manner (NTSB, 2017). While it was not published as a contributing factor to the accident, the NTSB Report discloses a claim made by the student that the flight instructor was engaged in a video chat on his cell phone during the downwind leg (NTSB, 2015). The final investigation proved inconclusive as to the use of the flight instructor's cell phone during the flight because of a locking feature on the phone preventing its access (NTSB, 2015). However, if the claim is valid, it could have potentially distracted the flight instructor from the state of the aircraft and led to his delayed response in recovery from the stall.

Currently, AC 91.21-1D only addresses flights operating under instrument flight rules (IFR) by stating that the operation of PEDs not installed aboard U.S.registered civil aircraft is prohibited while operating under IFR (FAA, 2017a). Flights operating under Part 91K, 121, and 135 are mainly filed under IFR, but general aviation (Part 91) flights are sometimes filed under visual flight rules (VFR). Based on the language of AC 91.21-1D, VFR flights would be exempt from this prohibition of PEDs in the cockpit (FAA, 2017a).

\section{Purpose Statement}

The purpose of this study is to probe pilots' use of unapproved PEDs on the flight deck and how closely pilots adhere to their organization's PED policy. The research evaluates PED use during different phases of flight, the independent variable in this case, and whether the PED became a distraction and led to errors or did not, which is the dependent variable. The study also investigates the reasons behind pilots' decisions to use PEDs despite policies which prohibit their use. For 
this survey, the definition of a PED is consistent with that outlined in AC 120-76D and considered to be any device used for functions not related to the flight. An EFB being used for non-essential functions is considered a PED. Otherwise, a PED could be a tablet, MP3 player, e-reader, laptop, or [most often] a cell phone.

The field study was completed in an area relating to aviation safety whereby the distractions caused by electronic devices on the flight deck are evaluated. These distractions have the potential to negatively impact the safety of flight, and many times the use of electronic devices still occur despite company policies or regulations stating otherwise. The findings of this research were compiled from survey results and presented here in a written report. From this study, it can be determined if pilots are more likely to use a PED in one phase of flight over another and why they continue to use them if they are prohibited. Understanding these details may shed some light on reasons for PED usage and assist in more proactive safety measures, like knowing what phase of flight is most likely to have PED distractions. If, for example, PED use at cruise is done in moderation and does not interfere with in-flight duties, but instead serves as stimulation during times of low workload, that can be further examined.

\section{Research Questions}

This study investigates the following questions:

1. Do pilots use PEDs during times when their use is otherwise prohibited?

2. Are PEDs causing distractions and errors on the flight deck?

3. Is there one phase of flight where PED use takes place more than another phase of flight?

\section{Method}

\section{Sampling}

The data for this field research was acquired from an online survey administered to a sample of Federal Aviation Regulations (FAR) Part 121 commercial airline pilots. The sample of FAR Part 121 commercial airline pilots was intended to represent the population of all FAR Part 121 commercial airline pilots. 20 pilots were selected by a nonrandom technique known as stratified sampling.

Pilots were chosen based on those who work at Part 121 airlines. Some pilots work for regional airlines, others at low-cost carriers (LCC), and some work for legacy carriers (also known as major carriers). The sample of pilots includes 
both male and female as well as different age groups ranging from 27 to 56 years of age.

\section{Instrument}

The study was administered with a 10-question, online survey as the data collection instrument. A survey was chosen as the instrument of choice instead of interviewing due to the sensitive nature of the survey topic dealing with intentional noncompliance. This also provided research subjects the ability to take this survey anonymously at their convenience in an environment where they felt comfortable.

To reassure the survey subjects of anonymity, the survey invitation emphasized the de-identification and confidentiality of the responses that were used as group data, not individual responses. Anonymity and confidentiality foster trust which help to ensure honesty from the research subjects for the most organic responses. The survey was intended to probe pilots' use of PEDs on the flight deck and reasons for their use despite being against policy.

\section{Procedures}

The survey included questions that address subjects' knowledge of the employer's PED policy, whether the pilots use PEDs despite this policy, the different phases of flight in which PEDs are used, whether they have caused the subject to make errors or become distracted, and some limited insight to why the subjects engage in the use of PED even when it may be prohibited. Because the survey was direct in asking about intentional noncompliance, there is a risk of dishonesty in the survey subjects. There was an attempt to mitigate this issue by emphasizing the confidentiality of the survey in the invitation letter sent by e-mail.

The first two questions regarding an employer's PED policy and the subject's knowledge of said policy were answered in a Yes, No, or I'm Not Sure format. The next seven questions had a choice of answers that resemble a 5-point Likert scale with answers ranging from "Rarely" to "Almost Always," except for the third question which had an additional selection for "My organization does not have a PED policy." The last question of the survey was both multiple choice and open-ended by having a comment box. The individual taking the survey could select more than one choice for why they use the PED even if it is prohibited, but there was also a place for the individual to type something of their choosing if deemed more appropriate.

Questions six through nine address the phase of flight, which is the independent variable. The independent variable was controlled by asking a 
different question for each phase of flight separately. Discrete variables that represent gender and age were not included in the survey questions, and therefore correlating data cannot be analyzed based on these variables.

\section{Limitations}

The study itself is limited in the population size, as a sample of 20 airline pilots is a small representation of the total number of airline pilots. It is an even smaller sample when the number of pilots is stratified between regional pilots, LCC pilots, and legacy pilots. Additionally, the type of route flown by the pilots may have different implications for PED usage based on length of the flight. For example, PED usage could be more frequent overall at LCC or legacy carriers due to the longer legs if pilots are using the PED as a form of stimulation while at cruise.

This survey instrument is limited in its abilities for a few reasons. The first one being the difficulty in gaining specific knowledge of why PED use occurs by nature of using a survey method. For this reason, an interview would prove a better method for learning more in-depth information from the research subjects.

Next, a 10-question limit prevented other specific data to be acquired such as questions which could probe the use of cell phones. For example, the study focuses on PED usage overall, but this is a broad category. Cell phones, which may be the most common PED used on the flight deck could have different implications than EFBs because they are considered transmitting devices whereas EFBs may not be (depending on the device). There is only one question in the survey which explicitly probes the use of cell phones, and that is Question 8.

Next, because the survey is limited to 10 questions, demographics corresponding to each subject's survey responses were not provided, only the overall demographics associated with the research sample. A question probing PED usage during taxi out (before takeoff) was not included due to the 10-question limitation as well as a question encompassing PED use at cruise altitude. These different types of questions could address the limitation mentioned above that restricts data by grouping all PED usage into one category instead of distinguishing the difference in cell phone use or EFB use, as an example. Lastly, the survey was created for this study, and its credibility cannot be assured as other industry data is not available to accompany some parts of this research.

\section{Results}




\section{Demographics}

The study sample included 20 FAR Part 121 commercial airline pilots. For gender, the sample contained 14 male pilots and six female pilots (See Fig. 1). The sample also represented a considerable variation in the age of pilots from 27 years of age to 56 years of age (See Fig. 2). There were five pilots aged 21-30 years, eight pilots aged 31-40 years, three pilots aged 41-50, and four pilots aged 51-60 years. Lastly, the sample included four pilots from regional airlines, five pilots from LCCs, and 11 pilots from legacy airlines (See Fig. 3).

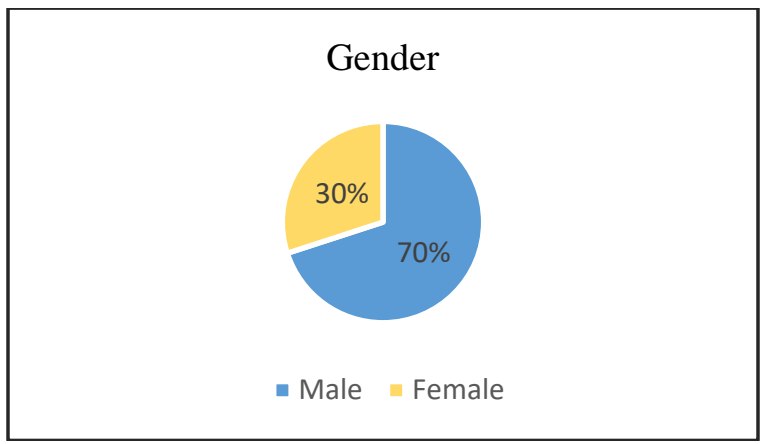

Figure 1. Breakdown of gender for the survey sample demographics.

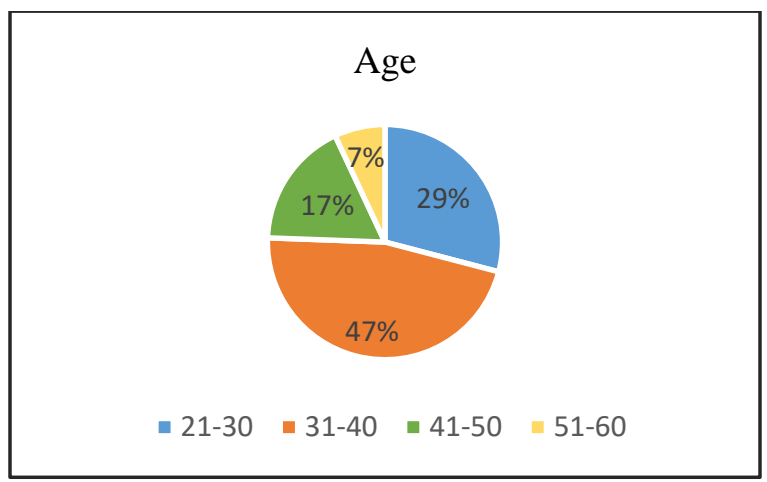

Figure 2. Breakdown of age for the survey sample demographics. 


\section{Category of Part 121 Airlines}

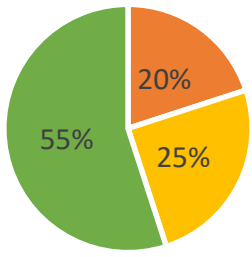

- Regional Pilots $\quad$ LCC Pilots $\quad$ Legacy Pilots

Figure 3. Breakdown of employing airline categories for the survey sample demographics.

\section{Knowledge of Company Policies}

Knowledge of company policies was addressed in the first three questions of the survey. Question 1 asked, "Does your company or organization have a policy against using PEDs on the flight deck?" There were three choices for this question: Yes, No, and I'm Not Sure. Of the 20 surveyed airline pilots, 85\% indicated that their operator had a policy in place for using PEDs on the flight deck. The remaining $10 \%$ answered that they were unsure of a policy, and the other $5 \%$ answered 'No' (See Fig. 4). Considering that the FAA banned the use of PEDs on the flight deck in 2014, it is likely that all 20 airline pilots who were surveyed do, in fact, have a company policy regarding PED usage on the flight deck. However, even if the company did not have a policy, the FAA's publication on April 14, 2014 Prohibition on Personal Use of Electronic Devices on the Flight Deck would still serve as a governing mandate (FAA, 2014a).

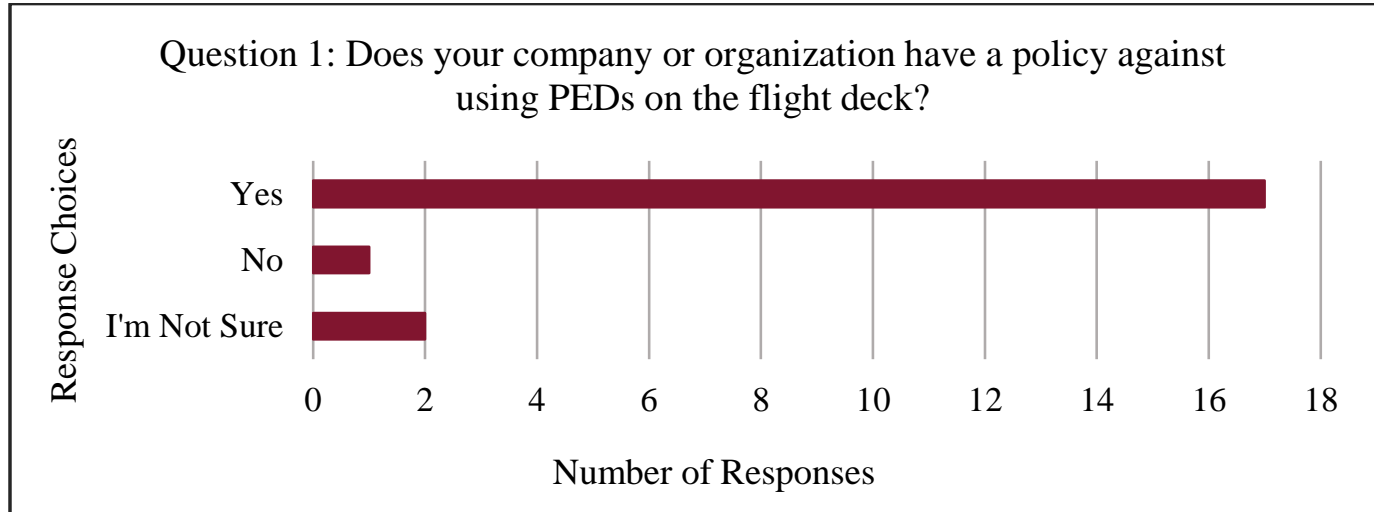

Figure 4. Graph depicting survey results from Question 1. Total number of survey respondents was 20 pilots. 
The second question targeted the pilot's familiarity with the policy. In some instances, a pilot may be aware that a policy exists but not what it states explicitly. In that scenario, we can assume a pilot may use the PED during a time they think is acceptable when it is not. Question 2 asked, "If your company or organization has a policy against using PEDs, are you aware of what the policy states?" There were three choices for this question: Yes, No, and I think so, but do not know for sure. Of the 20 surveyed airline pilots, $70 \%$ were aware of what their company's PED policy states. The remaining $20 \%$ were not sure what the policy explicitly outlined, and the other $10 \%$ reported that they do not know what the policy states (See Fig. 5).

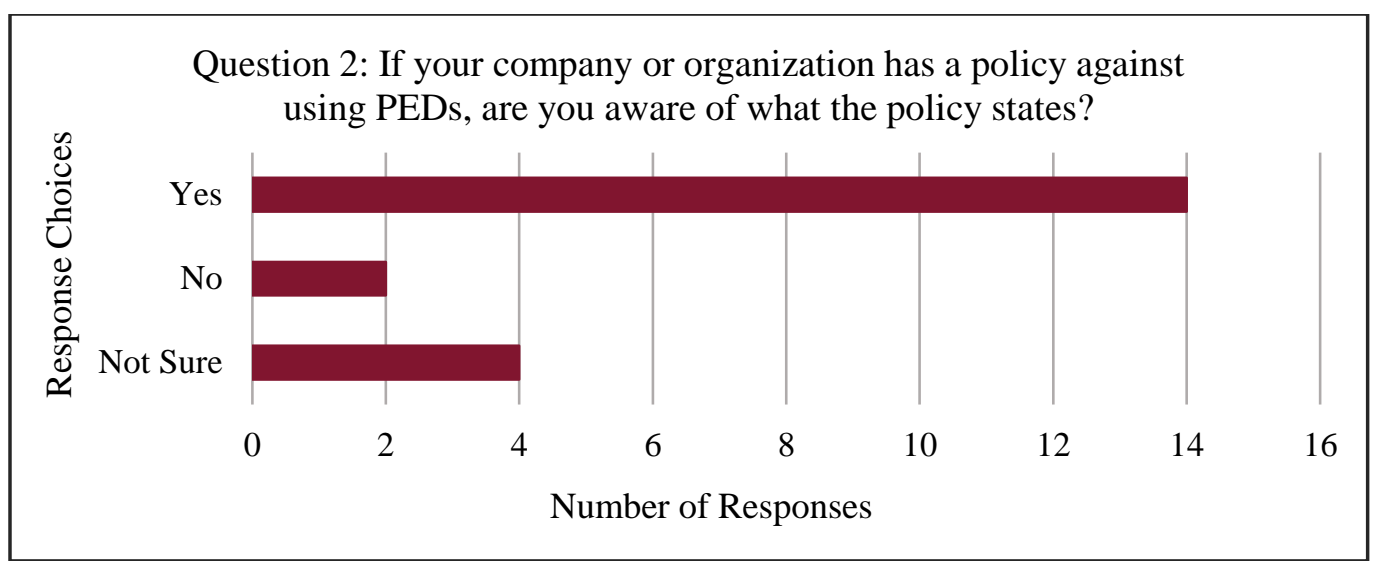

Figure 5. Graph depicting survey results from Question 2. Total number of survey respondents was 20 pilots.

The third question targeted the pilot's opinion on whether they think the PED policy is appropriate or not. This is important when considering a pilot's willingness to comply with the policy. If he/she does not believe it is appropriate, that the pilot may not respect the rule; alternatively, the pilot may have more respect for adherence if they support it. Additionally, a comment section accompanied this question for survey subjects to include their opinion of how it could be changed or improved.

Question 3 asked, "Do you think that your organization's PED policy is appropriate or is there something that you would change if you could?" There were six choices for this question: Very Appropriate, Somewhat Appropriate, Neutral, Somewhat Inappropriate, Very Inappropriate, and My Organization Does Not Have a PED Policy. When asked if they thought the PED policy was appropriate, only $20 \%$ of the survey subjects reported the policy was 'Very Appropriate.' The majority, $45 \%$ of the pilots, said it was 'Somewhat Appropriate,' $25 \%$ of the pilots 
reported 'Neutral' feelings for the policy, and the remaining $10 \%$ said it was 'Somewhat Inappropriate' (See Fig. 6).

The selection 'My Organization Does Not Have a PED Policy' in Question 3, was not selected even though one survey subject answered Question 1 - whether their company had a PED policy - with a 'No.' This may have thrown off the results slightly but was only one person which equaled $5 \%$ of the results. For those who thought their company's PED policy could be improved upon, the reasons varied from: "the policy should be somewhat flexible on the phase of flight," "at final cruise leniency should exist," to "cannot access weather radar information before takeoff under current policy." These comments show that many pilots would probably support a change in the policies and indicate that PED usage is variable based on the phase of flight.

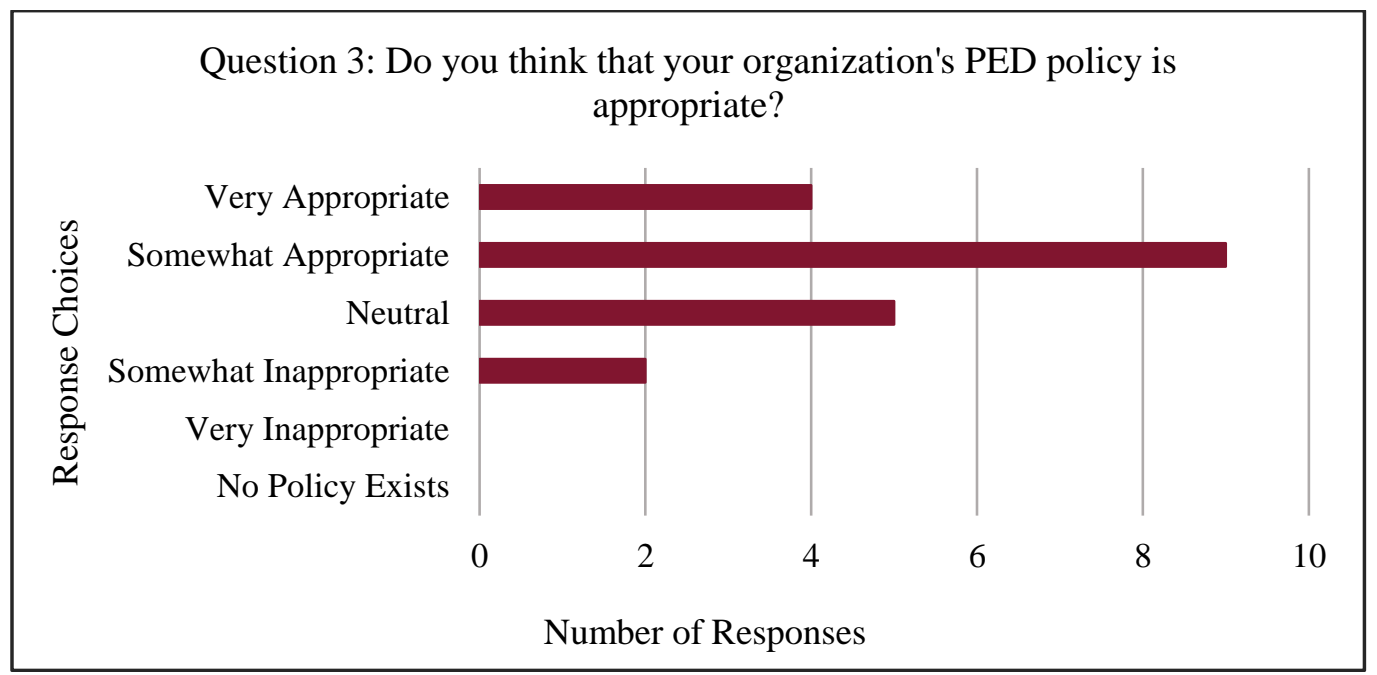

Figure 6. Graph depicting survey results from Question 3. Total number of survey respondents was 20 pilots.

\section{Personal Usage}

The fourth question focused on pilots' use of PED in accordance with or against company policy. Specifically, this question was meant to probe how many pilots use PEDs on the flight deck even if their company policy dictates otherwise. Question 4 asked "Many pilots will use PEDs (not including electronic flight bags) even though they know it is against policy. Do you ever find yourself doing the same?" There were five choices for this question: Never, Rarely, Sometimes, Frequently, and Every Time I Fly. Of the 20 individuals surveyed, $45 \%$ of the pilots reported that they 'Frequently' use their PEDs on the flight deck, and another $45 \%$ 
reported that they 'Sometimes' use their PEDs on the flight deck, for a total of $90 \%$ of the survey subjects. The remaining $10 \%$ was split down the middle with $5 \%$ of the pilots saying they 'Never' use their PED on the flight deck and 5\% of the pilots saying they 'Rarely' use their PED on the flight deck (See Fig. 7).

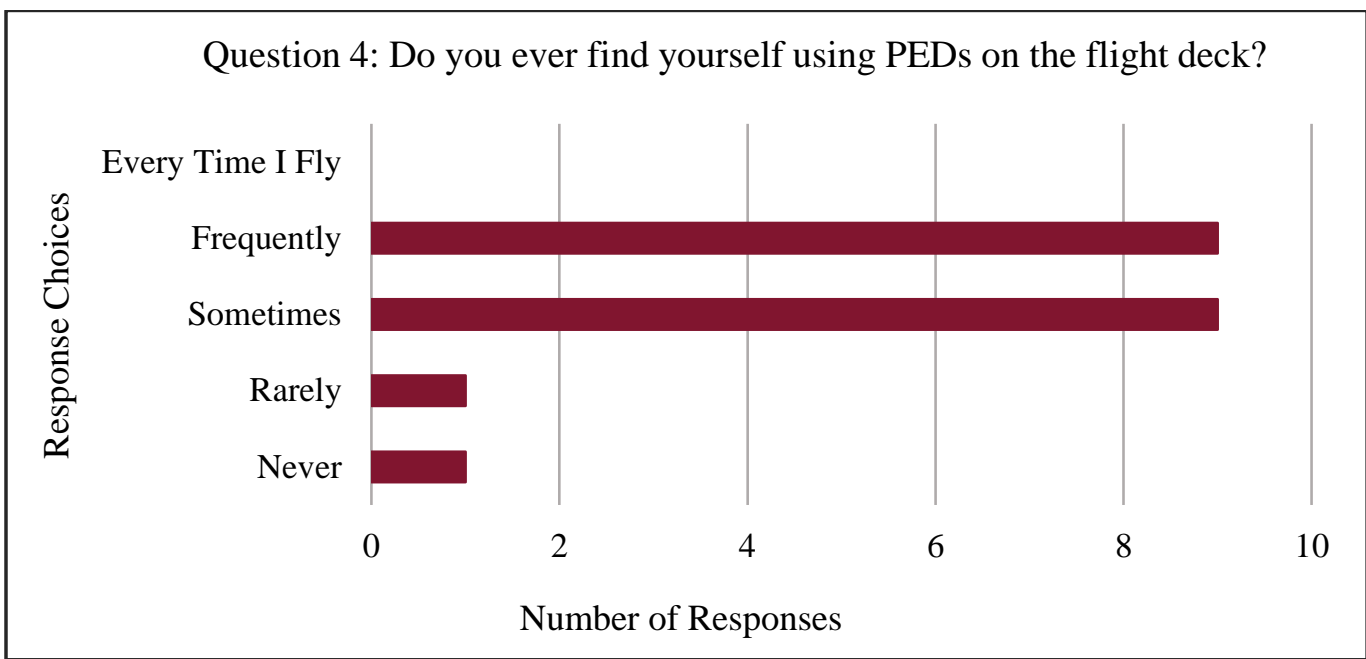

Figure 7. Graph depicting survey results from Question 4. Total number of survey respondents was 20 pilots.

The fifth question queried if the use of PEDs on the flight deck has caused the pilots to become distracted or make errors. Question 5 asked, "Has the use of PEDs caused you to become distracted or make mistakes?" There were five choices for this question: Never, Rarely, Sometimes, Frequently, and Almost Every Time. The majority, $60 \%$, of pilots stated that it 'Rarely' led to mistakes, and $20 \%$ reported that it has 'Never' led to a mistake. The other $20 \%$ reported that it 'Sometimes' led to errors (See. Fig. 8). Given both the statistics from the NTSB as well as the [documented] correlating incidents and accidents, it is known that PEDs can cause distractions for pilots on the flight deck (NTSB, 2013b).

From this data, though, we can see that distractions or errors do not occur much of the time. However, this does not minimize the fact that the risk is high enough that it only takes one error to be catastrophic. The next section will specifically probe the different phases of flight to determine if PED usage occurs in one phase more than another. 


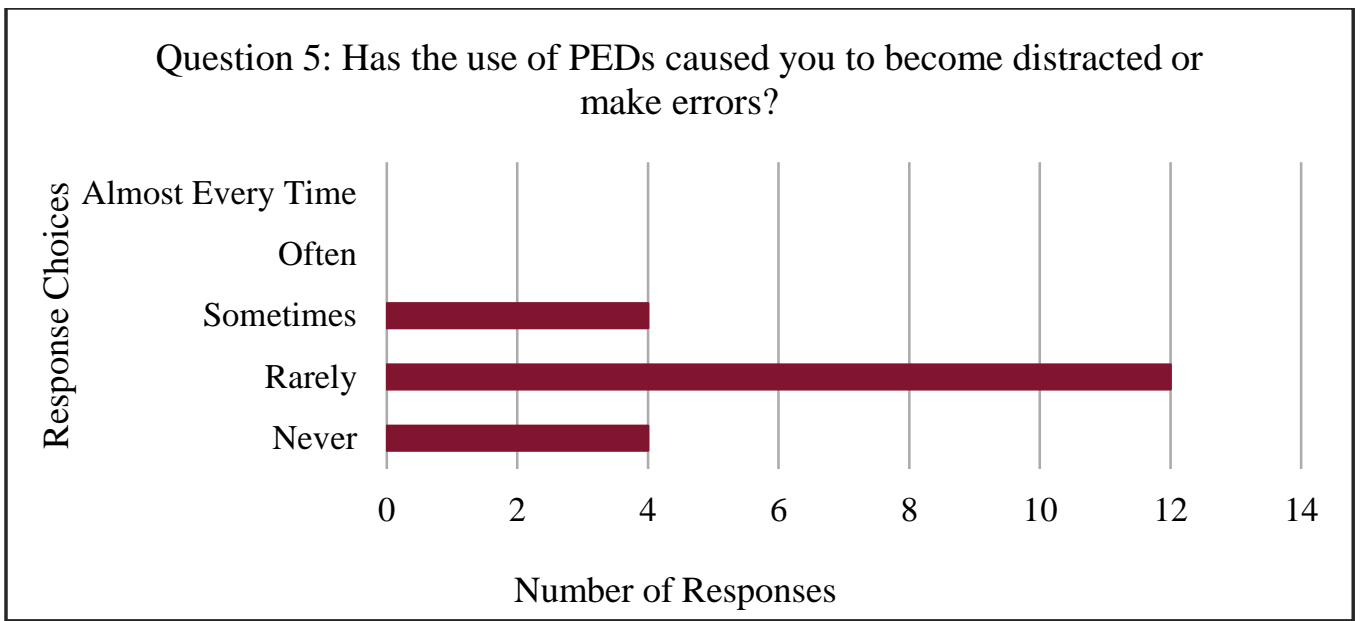

Figure 8. Graph depicting survey results from Question 5. Total number of survey respondents was 20 pilots.

\section{Phases of Flight}

The sixth question considered the use of PEDs before pushback from the gate during the preflight preparation phase. Question 6 asked, "Have you ever delayed doing a preflight task because of a PED distraction?" There were five choices for this question: Never, Rarely, Sometimes, Frequently, and Almost Always. It appeared PED use was frequent during the preflight phase of flight; $10 \%$ of pilots reported that they 'Often' delay a preflight task due to a PED distraction and $30 \%$ of pilots reported that they 'Sometimes' delay a preflight task. Conversely, $30 \%$ of the pilots reported 'Rarely' delaying a preflight task, and $30 \%$ of the pilots reported 'Never' delaying a preflight task for PED distractions (See Fig. 9). Referencing the Final Accident Report from the air ambulance crash in Mosby, Missouri, it was determined that excessive cell phone use be a contributing factor to that accident (NTSB, 2013a). This accident showcases that essential tasks and checks can get missed during the preflight preparation if PEDs become a distraction.

The seventh question asked survey subjects about their PED usage at cruise altitude and if it ever led to missed radio calls. Question 7 asked, "Have you ever missed a radio call at altitude because of a PED distraction?" There were five choices for this question: Never, Rarely, Sometimes, Frequently, and Almost Always. During the cruise phase of flight, $35 \%$ of survey subjects reported that they 'Never' have missed a radio call because of a PED distraction. The majority (55\%) of surveyed pilots stated that they have 'Rarely' missed a radio call because of a PED distraction. The remaining $10 \%$ of pilots reported they have 'Sometimes' missed radio calls at cruise altitude (See Fig. 10). 


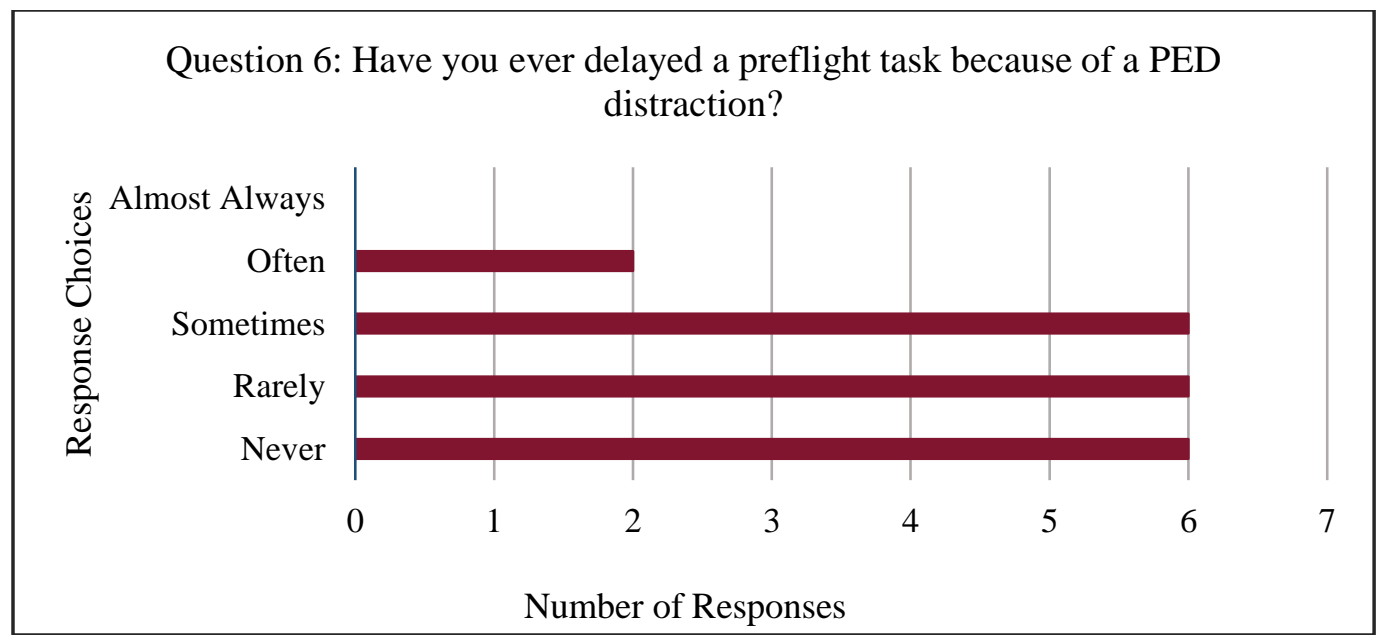

Figure 9. Graph depicting survey results from Question 6. Total number of survey respondents was 20 pilots.

Many of the surveyed pilots provided comments for Question 10 stating that they feel PED use should be allowed at cruise altitude because they do not believe it negatively affects their performance on the flight deck. One survey subject wrote: "In regards to [Question] \#7, I miss radio calls when not using a PED also". In fact, there are times that discussion alone (which is approved above 10,000 feet) can cause significant distraction. That said, an argument can be made supporting the fact that regardless if the item in question is approved or unapproved - PEDs, newspapers, books, electronic flight bags (EFBs), or just cockpit conversation - it can be distracting and ultimately needs to be managed by the pilots (Hopkins, 2013).

The eighth question probed survey subjects specifically about their cell phone usage on final approach, regarding turning the phone on to get personal notifications pushed through before landing. Question 8 asked, "Have you ever turned your phone on during final approach to get your messages/notifications pushed through before landing?" There were five choices for this question: Never, Rarely, Sometimes, Frequently, and Almost Always. During the approach to landing phases, an overwhelming $75 \%$ of pilots reported that they 'Never' turn their phone on early. Other pilots reported that they 'Rarely' turn their phone on early $(10 \%)$ and $5 \%$ reported 'Sometimes' turning their phone on early (See Fig. 11). 
Question 7: Have you ever missed a radio call at altitude because of a PED distraction?

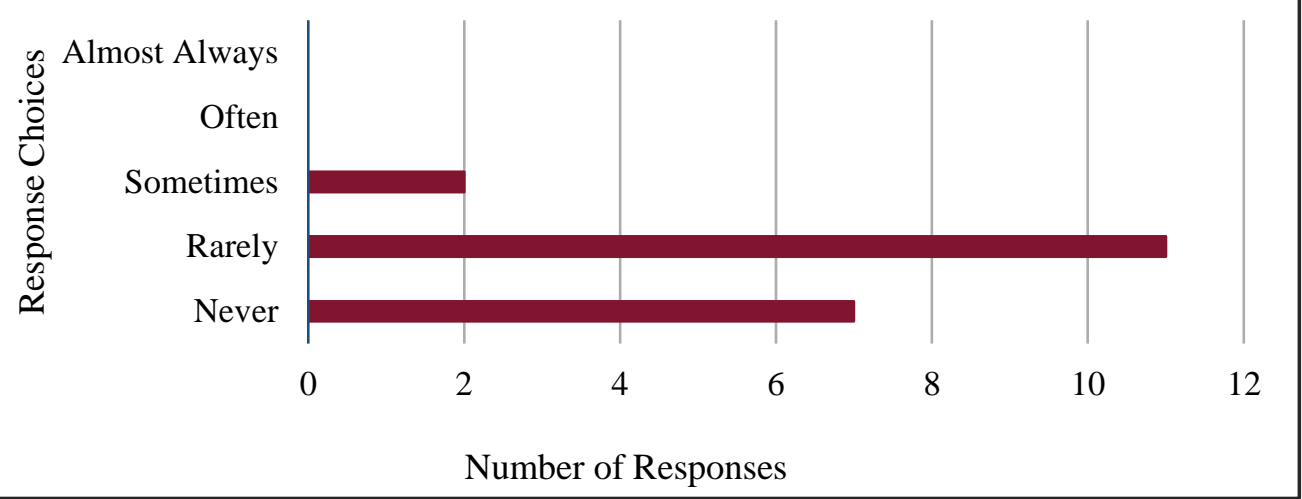

Figure 10. Graph depicting survey results from Question 7. Total number of survey respondents was 20 pilots.

Only $10 \%$ of pilots reported that they 'Often' turn their phone on during final approach. Even though this is the minority of pilots surveyed, this action can pose significant risk by causing an undue distraction during a critical phase of flight. If the messages have audible alerts, this will likely be a distraction to the pilots during landing as well as a violation of the sterile cockpit concept (FAA, 2009).

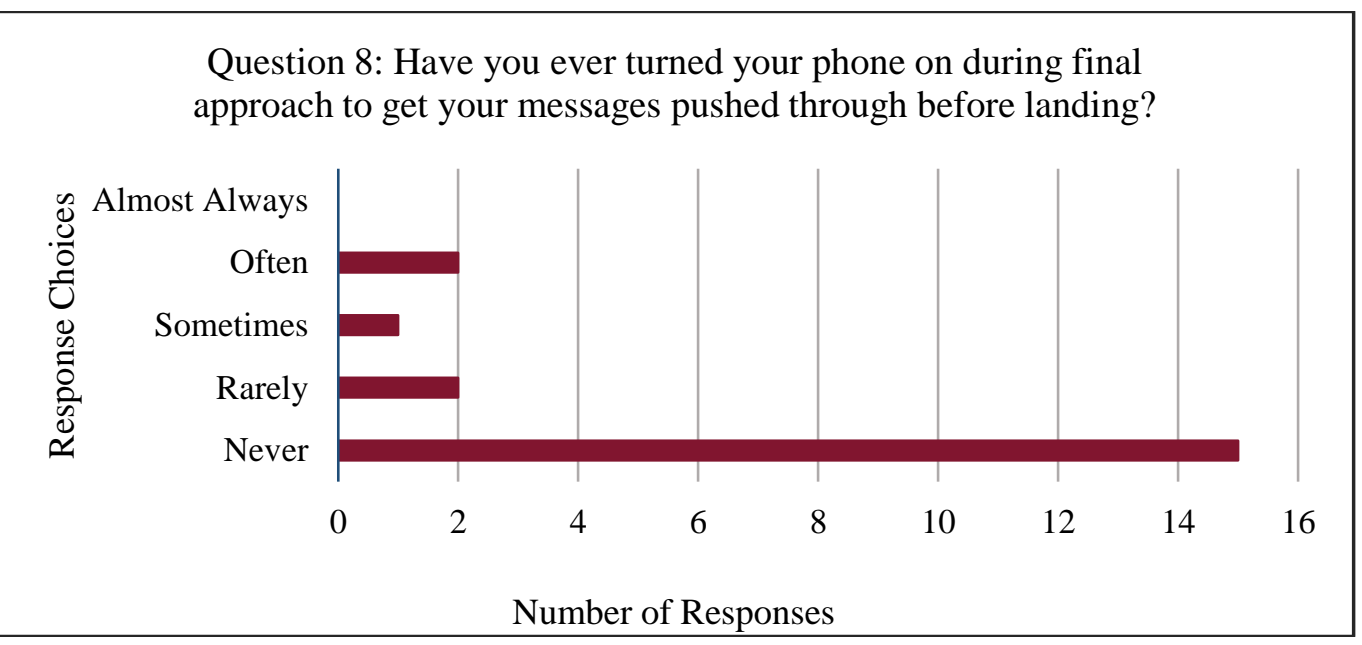

Figure 11. Graph depicting survey results from Question 8. Total number of survey respondents was 20 pilots. 
The ninth question investigated PED usage after the flight is completed, but the aircraft has not entirely completed the block in process at the gate. Question 9 asked, "Have you ever delayed doing an after-landing/parking/shutdown checklist task because of a PED distraction?" There were five choices for this question: Never, Rarely, Sometimes, Frequently, and Almost Always. Before the flight is officially completed at the gate, $60 \%$ of pilots reported that they 'Never' delay an after-landing task due to a PED distraction. As little as 35\% of pilots reported they 'Rarely' delay an after-landing task for a PED distraction, and only 5\% of pilots reported that they 'Sometimes' delay an after-landing task (See Fig. 12).

Though the actual flight is finished, parking at the gate is just as critical of a phase of flight as the others. Safely parking at the gate entails shutting down engines, making sure the aircraft is appropriately powered, and ensuring that the parking brake is set. These actions can have a direct impact on the safety of ground personnel as well as the care of the aircraft. There have been times when distracted pilots left the aircraft with engines running or no power connected, leading to drained batteries and ultimately delayed flights.

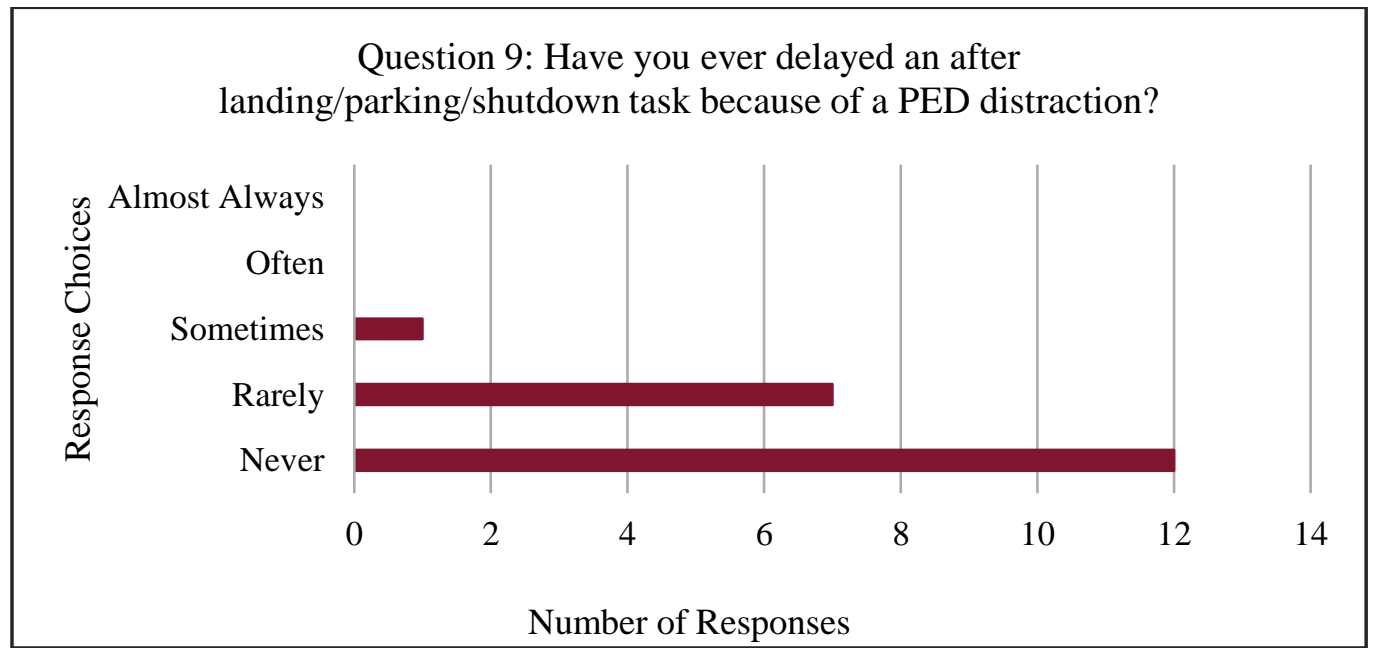

Figure 12. Graph depicting survey results from Question 9. Total number of survey respondents was 20 pilots.

Based on the data acquired through this field study it appears a device is used most often during the preflight phase where $40 \%$ of pilots reported using the device and delaying preflight tasks either 'Often' or 'Sometimes. It may be assumed based on specific comments from survey respondents that the PEDs are also used often during cruise altitude, but that is not supported by the data of this study. The survey question only probed whether PED use led to missed radio calls. Referring 
to the previous limitations section, PED use during taxi as well as at cruise altitude are two questions that should be included in this study is conducted more in-depth in the future.

\section{Reasons for the Use of Portable Electronic Devices}

The last question attempted to target the 'why' behind PED use on the flight deck and was offered to survey subjects as a 'select all that apply' option. While there were 20 survey respondents, there was a total of 53 responses as many respondents checked more than one choice. Question 10 asked, "If using a PED on the flight deck is prohibited or causes you to make mistakes, why still use it?" There were six choices for this question: I only do it on long flights (2.5 hours plus), I do it when I have a poor cockpit dynamic and am not conversing with the other pilot, I am bored, and it keeps me stimulated, I only do it in case of emergencies or am anticipating a particular message (e.g. family emergency, illness), I do not believe that it negatively affects my performance on the flight deck, and Other. The other choice also had a comment section for respondents to fill in feedback or reasons of their choosing.

The need for stimulation at cruise altitude was reported by $75 \%$ of the survey subjects which mirrors the Human Factors concept that low workload can be just as detrimental to performance as high workload (See Fig. 13). Half of the subjects reported that they use PEDs at cruise because they have a poor cockpit dynamic and there is very little engagement going on between the two pilots. From this, it can be inferred that the PED substitutes as stimulation instead of conversation. A little more than half of the pilots $(55 \%)$ stated that they do not believe PED usage negatively affects their flight deck performance. One person wrote: "Cruise flight, Autopilot on, no change in the state of the aircraft" as a validation for a low workload during cruise and, ultimately, a time with minimal distractions. The need for stimulation was further validated by $35 \%$ of pilots reporting they only use PEDs on long flights that are 2.5 hours or more.

The lowest figure was represented by $15 \%$ of pilots who stated they only use PEDs though prohibited because of a family emergency. Some individuals made references to better resources for weather or applications that help them operationally: "I have apps on my own devices that are better or supplement company manuals and devices. For instance, WX radar and notes that keep getting erased or moved in my manuals". Many of the comments provided in the 'Other' category relate to using PEDs on the flight deck as a form of stimulation during times of low workload. Below are some of the comments: 
- "It helps for research on cockpit conversations."

- "I read when at altitude in low workload environment. I use PED instead of a book for several reasons."

- "PED's are integrated into our lives. There is no way to remove them. In a 727 the crew read books. Against the rules - yes but still done. In 2017 people look at their phones. It just is, and it will not stop. So don't bother trying"

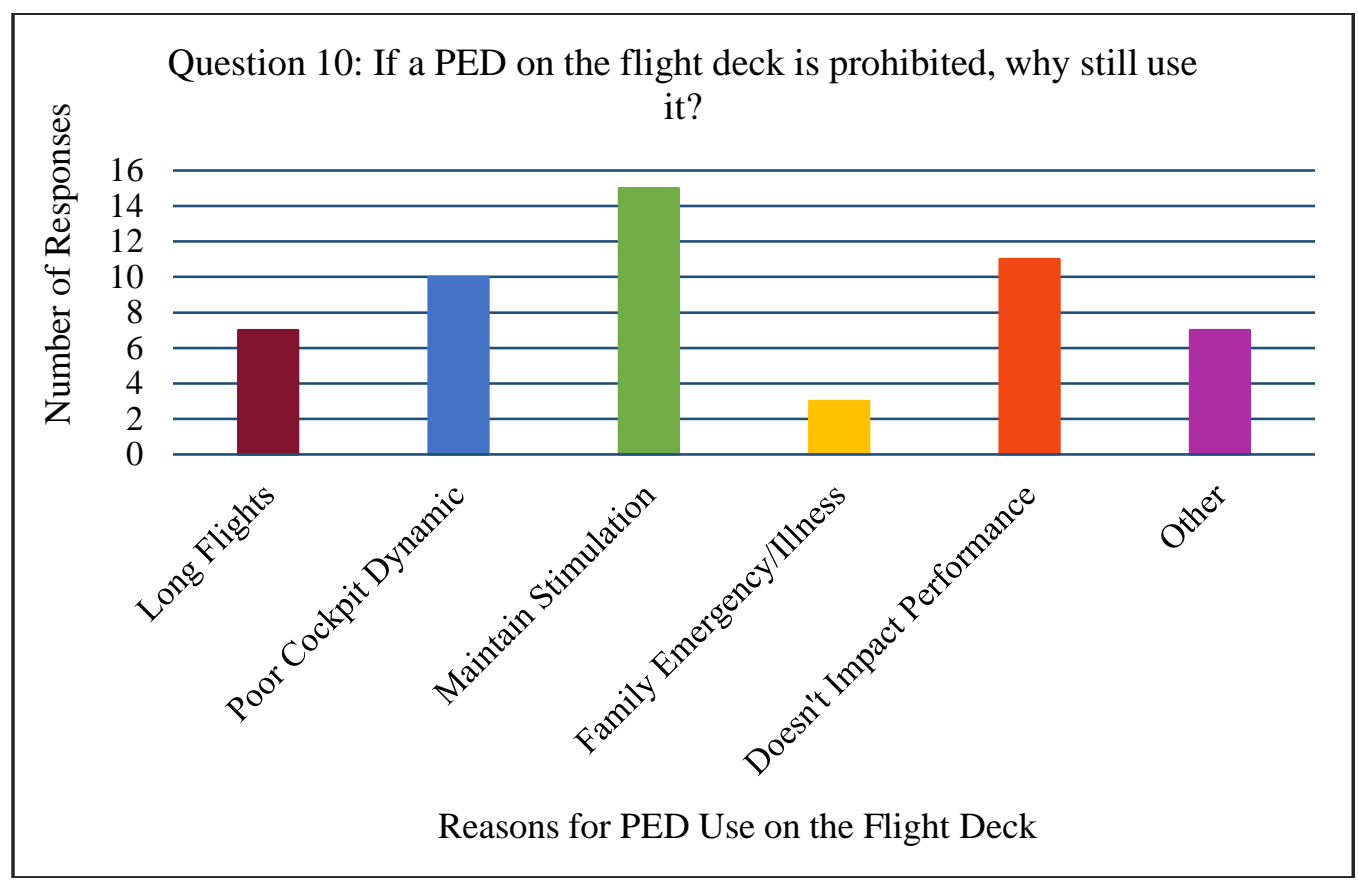

Figure 13. Graph depicting survey results from Question 10. Total number of survey respondents was 20 pilots, while there were 53 total responses due to the ability to select multiple answers of their choosing.

\section{Recommendations}

As an industry, it is safe to say we are probably nowhere near PEDs being approved for use on the flight deck, if ever. There is enough supporting evidence to prove PEDs cause distractions which can lead to serious incidents or accidents. However, Human Factors research has shown that pilots' performance suffers during times of low workload just as it does during high workload. Based on some of the responses from the pilots who were surveyed, it is worth considering or at least exploring, an approval for PED usage during cruise flight in times of low workload. It appears that even with the FAA ruling in 2014 banning PED usage on the flight deck, pilots are still using them anyways. 
If pilots can use discipline to manage their activities, it seems realistic to allow them access to PEDs so long as the devices do not interfere with duties or become a distraction. Pilots may be less inclined to use devices during critical phases of flight (e.g., preflight, taxi, landing) if they have access to PEDs during cruise flight. The delicate balance is for pilots to realize when the PED has become a distraction instead of a means for low-workload-stimulation. There is a gamble in this approval in that allowing access to PEDs during times of low workload could lead to abuse of the policy.

All of this said, allowing PEDs on the flight deck will carry risk and ultimately liability in the event of an incident or accident. There is a lot of 'grayarea' in allowing PED use and the benefits do not necessarily outweigh the risk. Therefore it is more prudent to prohibit their use altogether. Human error is inevitable, and intentional noncompliance will never go away. For this reason, it is likely the FAA will never allow PED use on the flight deck.

The research conducted here, though small in scale, was intended to shed light on a more significant, technology-driven concern. Reliance on electronic devices and constant stimulus is an issue that has serious safety implications. This introductory study highlights the need for research of a greater scope on this subject matter. Future studies would benefit from a larger population as well as a wider variety of survey questions for a statistical analysis of data.

Based on some of the limitations of this research, follow-up studies should incorporate more questions to achieve enhanced data acquisition. More questions would allow for data stratification related to the demographic-type discrete variables gender, age group, or employing airline categories. For example, data of this nature could be beneficial by potentially showing a correlation between employing airline categories (long versus short flights) and PED usage at cruise flight. Alternatively, data could show if a correlation exists between age and PED usage. A survey with additional questions can also examine the different phases of flight more thoroughly. Lastly, additional questions could probe the specific types of PEDs used and make a distinction between cell phones, EFBs being used for personal use, or 'other' PEDs such as MP3 players, laptops, or e-readers. There is no doubt, though, that this topic merits further review.

\section{Conclusion}

Overall, this study shows that most pilots still use PEDs even though they are prohibited. There are still some pilots that do not use them on the flight deck at all, but most pilots do use PEDs knowing full well that it is against policy. 
Understanding the reliance on PEDs in today's world, and possibly even the theorized addiction, it seems difficult (if not impossible) for pilots to avoid using them at all. Many pilots report using the PED while maintaining the position that the devices, for the most part, do not cause distractions or errors.

The use of PEDs seems to be a modern-day stimulus at cruise altitude rather than a malicious act of noncompliance. As aviation has evolved, technology has reduced workload, so pilots nowadays find themselves in periods of little to no workload, especially during the cruise phase of flight. Before the days of PEDs, many pilots read books or newspapers to maintain a level of alertness. There are times when non-mission oriented cockpit discussion, though it is an approved activity, can also contribute to distraction. Whether the chosen activity to keep oneself busy is approved or unapproved, it is up to the pilot to manage those activities before they become distractions. For now, PED usage on the flight deck remains prohibited by both the FAA and the airlines, with no discussion about alleviating the rule. 


\section{References}

Federal Aviation Administration. (2009, February 4). Safety Alert for Operators 09003: Cellular Phone Usage on the Flight Deck. U.S. Department of Transportation. Retrieved from https://www.faa.gov/other_visit/aviation_industry/airline_operators/airline _safety/safo/all_safos/media/2009/SAFO09003.pdf

Federal Aviation Administration. (2014a). U.S. Federal Register: Prohibition on Personal Use of Electronic Devices on the Flight Deck. U.S. Department of Transportation. Retrieved from https://www.federalregister.gov/documents/2014/02/12/201402991/prohibition-on-personal-use-of-electronic-devices-on-the-flightdeck

Federal Aviation Administration. (2014b). Information for Operators 14006: Prohibition on Personal Use of Electronic Devices on the Flight Deck. U.S. Department of Transportation. Retrieved from https://www.faa.gov/other_visit/aviation_industry/airline_operators/airline _safety/info/all_infos/media/2014/InFO14006.pdf

Federal Aviation Administration. (2017a). Advisory Circular 91.21-1D: Use of Portable Electronic Devices Aboard Aircraft. U.S. Department of Transportation. Retrieved from https://www.faa.gov/documentLibrary/media/Advisory_Circular/AC_91.2 1-1D.pdf

Federal Aviation Administration. (2017b). Advisory Circular 120-76D: Authorization for Use of Electronic Flight Bags. U.S. Department of Transportation. Retrieved from https://www.faa.gov/documentLibrary/media/Advisory_Circular/AC_12076D.pdf

Hopkins, Jay. (2013, March 8). The human factor: Dangerous distractions. Retrieved from http://www.flyingmag.com/technique/proficiency/humanfactor-dangerous-distractions 
National Transportation Safety Board. (2010a). Aircraft accident report: NTSB/AAR-10/01 PB2010-910401. Loss of control on approach: Colgan Air, Inc. aperating as Continental Connection flight 3407. Washington DC: National Transportation Safety Board. Retrieved from https://www.ntsb.gov/investigations/AccidentReports/Reports/AAR1001.p df

National Transportation Safety Board. (2010b). NTSB news release: NTSB says Northwest pilots' distraction led to overflight of Minneapolis, notes ATC shortcomings; issues recommendations on ATC procedures. Washington DC: National Transportation Safety Board. Retrieved from https://www.ntsb.gov/news/pressreleases/Pages/NTSB_Says_Northwest_Pilots_Distraction_led_to_Overfli ght_of_Minneapolis_Notes_ATC_Shortcomings;_Issues_Recommendatio ns_on.aspx

National Transportation Safety Board. (2010c). Aircraft accident report: NTSB/AAR-10/05 PB2010-910405. Midair collision over Hudson River. Washington DC: National Transportation Safety Board. Retrieved from https://www.ntsb.gov/investigations/AccidentReports/Reports/AAR1005.p df

National Transportation Safety Board. (2013a). Aircraft accident report:

NTSB/AAR-13/02 PB2013-104866. Crash following loss of engine Power due to fuel exhaustion. Washington DC: National Transportation Safety Board. Retrieved from https://www.ntsb.gov/investigations/AccidentReports/Reports/AAR1302.p df

National Transportation Safety Board. (2013b). NTSB Safety Alert 025: Avoid Nonoperational Use of Portable Electronic Devices (PEDs) Before and During Flight. U.S. Department of Transportation. Retrieved from https://www.ntsb.gov/safety/safety-alerts/Documents/SA_025.pdf

National Transportation Safety Board. (2014). NTSB Most Wanted List: Critical changes needed to reduce transportation accidents and save lives. Retrieved from https://www.ntsb.gov/safety/mwl/Documents/2014/03_MWL_EliminateD istraction.pdf 
National Transportation Safety Board. (2015, January 27). NTSB aviation accident final report: CEN14FA265. Washington DC: National Transportation Safety Board. Retrieved from https://app.ntsb.gov/pdfgenerator/ReportGeneratorFile.ashx?EventID=201 40531 X12318\&AKey $=1 \&$ RType $=$ Final $\&$ IType $=$ FA

National Transportation Safety Board. (2017, March 6). NTSB aviation accident final report: ERA15FA085. Washington DC: National Transportation Safety Board. Retrieved from https://app.ntsb.gov/pdfgenerator/ReportGeneratorFile.ashx?EventID=201 $41229 X 15321 \&$ AKey $=1 \&$ RType $=$ Final $\&$ IType $=$ FA

Paz de la Puente, M., Balmori, A., \& Garcia, P. (2007). Addiction to cell phones: are there neurophysiological mechanisms involved? Proyecto, 61, 8-12. 